biologic naive vs experienced may help clinicians tailor treatment decisions to pts needs.

Objectives: This study aimed to compare DMARD initiation events in biologic naïve vs experienced pts.

Methods: In the Corrona registry (as of $2 / 28 / 2018$ ), we selected DMARD initiation events (with at least one 6-month follow up) and stratified them on whether the initiator was biologic naive or experienced. We compared pts baseline characteristics (demographic, clinical, treatment) between strata. We used Kaplan-Meier curves to describe time to discontinuation and log rank test to assess differences in persistence.

Results: For 48,246 RA pts, 10,347 DMARD initiations (index date, baseline; on $11 / 2012$ or thereafter) in 6,858 adults were identified. Within initiations, $38 \% \quad(n=3,931)$ occurred in bDMARD naïve pts. Females comprised $76 \%$ (naive) vs $80 \%$ (experienced). Despite comparable age and retirement status (Table), the bDMARD experienced initiators had RA for longer (mean: 12.6 vs 5.4), were more likely to be disabled (19.6\% vs $11.0 \%$ ), had marginally higher CDAl scores (mean: 19.1 vs 17.6), were more likely to discontinue index treatment due to elevated CDAI $(15.5 \%$ vs $10.9 \%$ ), and had a shorter treatment duration (mean: 13.8 vs 15.1 months) than bDMARD naïve initiators. Persistency was higher in the bDMARD naïve than in experienced initiators (Figure)

Conclusion: The marked difference in RA duration and pts disability status, despite comparable age, confirms prior reports that bDMARD experienced pts do not respond as well to therapy as bDMARD naïve pts. The increased CDAl scores and shortened durability of response suggests that there is still a need for new efficacious and well-tolerated RA therapy.

Table. Patient and treatment characteristics

\begin{tabular}{|c|c|c|c|c|c|c|c|}
\hline \multirow[t]{2}{*}{ Characteristics } & \multicolumn{2}{|c|}{ All initiations } & \multicolumn{2}{|c|}{ bDMARD Naîve } & \multicolumn{2}{|c|}{$\begin{array}{l}\text { bDMARD } \\
\text { Experienced }\end{array}$} & \multirow{2}{*}{ p-value } \\
\hline & $N=10,347$ & $100 \%$ & $\mathrm{~N}=3931$ & $38 \%$ & $\mathrm{~N}=6416$ & $62 \%$ & \\
\hline \multicolumn{8}{|l|}{ Demographics } \\
\hline Female & 8154 & 78.8 & 2992 & 76.1 & 5162 & 80.5 & $<0.0001$ \\
\hline Age (years), mean (SD) & 58.9 & 12.7 & 58.9 & 13.3 & 58.9 & 12.4 & 0.8 \\
\hline Disabled & 1688 & 16.3 & 433 & 11.0 & 1255 & 19.6 & $<0.0001$ \\
\hline Retired & 3012 & 29.1 & 1220 & 31.0 & 1792 & 27.9 & \\
\hline RA Duration (years), mean (SD) & 9.9 & 9.9 & 5.4 & 7.9 & 12.6 & 10.1 & $<0.0001$ \\
\hline CDAl, mean (SD) & 18.5 & 13.8 & 17.6 & 14.1 & 19.1 & 13.7 & $<0.0001$ \\
\hline \multicolumn{8}{|l|}{ Therapy allocation (n, \%) } \\
\hline Monotherapy & 3366 & 32.5 & 1496 & 38.1 & 1870 & 29.1 & $<0.0001$ \\
\hline Combination therapy & 6981 & 867.5 & 2435 & 61.9 & 4546 & 70.9 & \\
\hline $\begin{array}{l}\text { Index treatment duration (months), mean } \\
\text { (SD) }\end{array}$ & 14.3 & 13.4 & 15.1 & 13.8 & 13.8 & 13.1 & $<0.0001$ \\
\hline \multicolumn{8}{|l|}{$\begin{array}{l}\text { Reasons for discontinuation of index } \\
\text { therapy }(n, \%)\end{array}$} \\
\hline One or more reasons & 4916 & & 1624 & & 3292 & & \\
\hline Safety $^{2}$ & 925 & 15.4 & 376 & 18.5 & 549 & 13.8 & $<0.0001$ \\
\hline Efficacy ${ }^{\circ}$ & 1446 & 24.1 & 383 & 18.8 & 1063 & 26.8 & $<0.0001$ \\
\hline $\operatorname{CDA} \mid>10^{\circ}$ & 1421 & 25.8 & 427 & 10.9 & 994 & 15.5 & $<0.0001$ \\
\hline
\end{tabular}

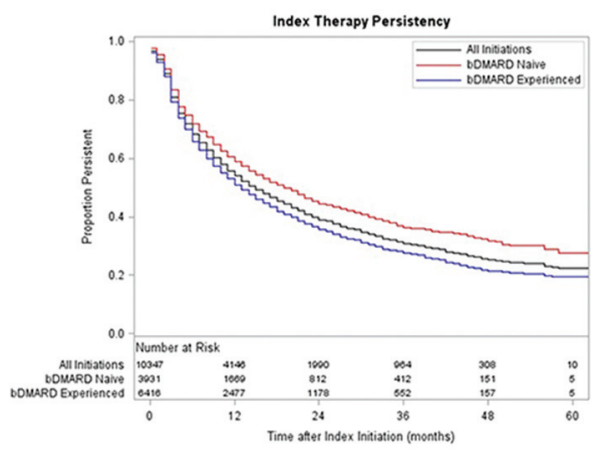

Acknowledgement: Study sponsored by Corrona, LLC. Corrona is supported by contracted subscriptions with multiple companies. Abstract was a collaboration between Corrona and Gilead with financial support by Gilead.

Disclosure of Interests: Robin K Dore Grant/research support from: Gilead Sciences, AbbVie, Amgen, Lilly, Pfizer, Regeneron, Sanofi, Consultant for: AbbVie, Amgen, Lilly, Speakers bureau: AbbVie, Amgen, Lilly, Sanofi, Regeneron, Pfizer, UCB, Leslie Harrold Grant/research support from: Pfizer, Consultant for: AbbVie, BMS, Genentech, Taylor Blachley Employee of: Corrona, LLC, Kelechi Emeanuru Employee of: Corrona, LLC, Jenya Antonova Shareholder of: Gilead Sciences, Employee of: Eli
Lilly and Company, Medimmune, Genentech, Gilead Sciences, Joel Kremer Grant/research support from: AbbVie, Genentech, Lilly, Novartis, Pfizer, Consultant for: AbbVie, Amgen, BMS, Genentech, Lilly, Regeneron, Sanofi, Pfizer

DOI: 10.1136/annrheumdis-2019-eular.1863

\section{SAT0143 SAFETY AND EFFECTIVENESS OF BIOLOGIC DISEASE- MODIFYING ANTIRHEUMATIC DRUGS IN ELDERLY PATIENTS WITH RHEUMATOID ARTHRITIS}

Raquel Freitas $^{1}$, Joao Eurico Fonseca ${ }^{2}$, Joaquim Polido-Pereira²,

Nathalie Madeira ${ }^{3}$, Luís Cunha Miranda ${ }^{3}$, Miguel Bernardes $^{4}$, Bruno

Miguel Fernandes ${ }^{4}$, Flavio Costa $^{5}$, Mariana Santiago ${ }^{5}$, Agna Neto ${ }^{6}$,

Soraia Azevedo ${ }^{7}$, João Madruga Dias ${ }^{8}$, Mara Couto ${ }^{9}$, Graça Sequeira ${ }^{10}$, Maria Jose Santos ${ }^{1} .{ }^{1}$ Hospital Garcia Orta, Rheumatology, Almada, Portugal; ${ }^{2}$ Hospital Santa Maria, Rheumatology, Lisbon, Portugal; ${ }^{3}$ Instituto Português Reumatologia, Lisboa, Portugal; ${ }^{4}$ Hospital São João, Rheumatology, Porto, Portugal; ${ }^{5} \mathrm{Hospital}$ Coimbra, Rheumatology, Coimbra, Portugal; ${ }^{6}$ Hospital Egas Moniz, Rheumatology, Lisbon, Portugal; 7 ULSAM, Rheumatology, Ponte de Lima, Portugal; ${ }^{8}$ Centro Hospitalar Médio Tejo, Rheumatology, Torres Novas, Portugal; ${ }^{9}$ Hospital São Teotónio, Rheumatology, Viseu, Portugal; ${ }^{10}$ Hospital Faro, Rheumatology, Faro, Portugal

Background: Elderly population with rheumatoid arthritis (RA) is increasing. However, these patients are frequently excluded from clinical trials and data on effectiveness and safety of biologic Disease-Modifying Antirheumatic Drug (bDMARD) is scarce.

Objectives: To assess the persistence of $1^{\text {st }}$ bDMARD and the effectiveness and safety of bDMARD among elderly ( $\geq 65$ years).

Methods: Prospective multicenter cohort-study of RA patients starting a $1^{\text {st }}$ bDMARD registered at Reuma.pt. Demographic and disease characteristics, comorbidities, medications, disease activity at baseline and follow up $(3,6$ and 12 months) and adverse events (AE) were compared between elderly and adult ( $<65$ years) patients. Treatment persistence was estimated using Kaplan-Meier analysis. Effectiveness was measured as EULAR crude response rates, LUNDEX corrected, and adjusted for baseline characteristics. Results: 2400 patients were included, of which 486 aged $\geq 65$ years (table 1). Crude median persistence in bDMARD was 19.7 months $(95 \%$ $\mathrm{Cl} 14-25)$ in adults and $14.5(95 \% \mathrm{Cl} 3-26)$ in elderly patients (log rank test, $\mathrm{p}=0.46$ ) (figure 1). EULAR response (crude and LUNDEX corrected) was similar in the two groups at 3 and 6 months (figure 2). After adjustment for baseline characteristics, response rate was inferior in elderly at 12 months $(p=0.01)$. There were $697 \mathrm{AE}$ reported. Except for infections, more common in elderly patients $(p=0.03)$, the rates of severe $A E$, opportunistic infection, allergic reactions, cancer or hospitalizations were similar in the two groups, as well as the time to $1^{\text {st }} \mathrm{AE}$ occurrence (figure 2). Conclusion: Our findings showed that persistence of $1^{\text {st }}$ bDMARD was similar in adults and elderly RA patients. Though elderly had more severe disease and comorbidities at baseline, bDMARD treatment was equally effective and safe in the short term. However, it is necessary to consider the greater risk of infection in elderly when prescribing a biologic.

\begin{tabular}{|c|c|c|c|c|}
\hline & Total & Adults & Eldery & Pvalue \\
\hline Female - $N(\%) \mathrm{N}=2400$ & $2038(85)$ & $1630(85.2)$ & $408(84)$ & \\
\hline $\begin{array}{l}\text { Disease duration till } 1^{\text {st }} \text { bDMARD in years }-N(\%) \\
N=2074\end{array}$ & $10.3(3.7-14.5)$ & $7.4(4-14)$ & $9.6(4-18)$ & $<0.01$ \\
\hline RF and/or anti-CCP positive - $\mathrm{N}(\%) \mathrm{N}=2400$ & $1693(70.5)$ & $1350(70.5)$ & $343(71)$ & \\
\hline Erosive disease $\cdot N(\%) N=1639$ & $1213(74)$ & $947(73)$ & $266(79)$ & \\
\hline Extraarticular manifestations $-\mathrm{N}(\%) \mathrm{N}=2400$ & $482(20)$ & $383(20)$ & $99(20.4)$ & \\
\hline Hypertension $-\mathrm{N}(\%) \mathrm{N}=1769$ & $530(30)$ & $381(27)$ & $149(43)$ & $<0.01$ \\
\hline Dyssipidemla - N (\%) N= 1769 & $141(8)$ & $107(7,5)$ & $34(10)$ & \\
\hline BMI - median \pm IQR N=1210 & $27(24-30)$ & $26(24-30)$ & $27(23-30)$ & \\
\hline Diabetes $-\mathbf{N}(\%) \mathrm{N}=1769$ & $148(8.4)$ & $98(7)$ & $50(14.3)$ & $<0.01$ \\
\hline Cardiovascular disease $-\mathrm{N}(\%) \mathrm{N}=1769$ & $134(8)$ & $107(7.5)$ & $24(10)$ & $<0.01$ \\
\hline DAS 28-ESR - mean \pm SD N=1295 & $5.6 \pm 1,3$ & $5.5 \pm 1.3$ & $5.7 \pm 1.3$ & 0.02 \\
\hline CDAI - mean \pm SD N=1069 & $29 \pm 13$ & $28 \pm 13$ & $31 \pm 15$ & 0.03 \\
\hline SDAI - mean \pm SD N=1023 & $31 \pm 14$ & $30 \pm 13$ & $33 \pm 16$ & 0.01 \\
\hline HAQ-DI - mean \pm SD N=1090 & $1.5 \pm 0.6$ & $1.4 \pm 0.6$ & $1 \pm 0.7$ & $<0.01$ \\
\hline \multicolumn{5}{|c|}{$\begin{array}{l}\text { Table 1- Baseline characteristics. N: number; IQR: interquartile range; SD: standard deviation; RF: Rheumatoid factor; } \\
\text { CCP: Cyclic Gitrullinated Peptide; BMI: Body Mass Index DAS: disease activity score, CDAI -clinical disease activity Index, } \\
\text { SDAI- simple disease activity index, HAQ-DI health assessment questionnaire-disability index. When p value }>0,05 \text { no } \\
\text { value is presented. }\end{array}$} \\
\hline
\end{tabular}

Table 1. Baseline characteristics. $\mathrm{N}$ : number; IQR: interquartile range; SD: standard deviation; RF: Rheumatoid factor; CCP: Cyclic Citrullinated Peptide; BMI: Body Mass Index DAS: disease activity score, CDAI -clinical disease activity Index, SDAI - simple disease activity index, HAQ-DI health assessment questionnaire-disability index. When $p$ value $>0,05$ no value is presented. 


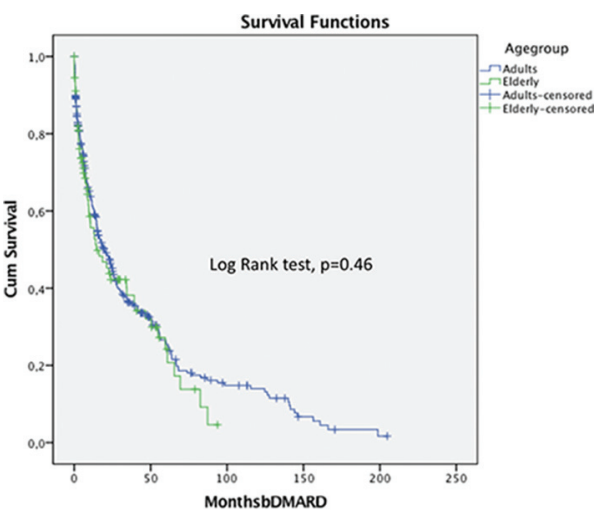

Figure 1 - Persistence in 1"s bDMARD (months) for elderly and adults

\begin{tabular}{|c|c|c|c|c|}
\hline Efficacy and safety & Total & Adults & Eldery & Pvalue \\
\hline EULAR response at 3 month (Lundex corrected) \% & $77.8(51)$ & $78.4(51)$ & $75(51)$ & \\
\hline EULAR response at 6 month (Lundex corrected) \% & $80.6(50)$ & $81.7(52)$ & $76(45.2)$ & \\
\hline EULAR response at 12 month (Lundex corrected) \% & $81.5(35.6)$ & $83.8(37)$ & $71.5(29.3)$ & 0,01 \\
\hline N patients with AE during 1st bDMAR & 409 & 319 & 90 & \\
\hline AE infection $-N(\%) N=407$ & $237(58,2)$ & $176(55,3)$ & $61(68,5)$ & 0,03 \\
\hline AE opportunist infection $-\mathrm{N}(\%) \mathrm{N}=408$ & $30(7,4)$ & $21(6,6)$ & $9(10)$ & \\
\hline AE allergic reaction $-N(\%) ~ N=407$ & $71(17,4)$ & $59(18,6)$ & $12(13,5)$ & \\
\hline Severe AEs- $N(\%) N=391$ & $82(21)$ & $64(21)$ & $18(20,9)$ & \\
\hline Hospitalization- $\mathrm{N}(\%) \mathrm{N}=407$ & $56(13,8)$ & $42(13,2)$ & $14(15,7)$ & \\
\hline bDMARD suspention due to $A E-N(\%) N=407$ & $171(42)$ & $130(40,9)$ & $41(46,1)$ & \\
\hline bDMARD reintrodution after AE- $\mathrm{N}(\%) \mathrm{N}=211$ & $61(28,8)$ & $48(30)$ & $13(25,5)$ & \\
\hline
\end{tabular}

Disclosure of Interests: None declared

DOI: 10.1136/annrheumdis-2019-eular.6076

\section{SAT0144 UNDERSTANDING THE LONG-TERM OUTCOME OF RITUXIMAB - IMPLICATIONS FOR MANAGEMENT}

Leticia Garcia-Montoya, MD Yuzaiful MD Yusof, Jean Baptiste Candelier, Andrew Rawstron, Edward Vital, Paul Emery. Leeds Institute for Rheumatic and Musculoskeletal Medicine, Leeds Biomedical Research Centre, Leeds, United Kingdom

Background: In patients with rheumatoid arthritis (RA), rituximab (RTX) is often prescribed after loss of response to TNF inhibitors; however, little is known about the long-term outcome of patients receiving treatment with RTX. Previous work $[1,2]$ has shown that aiming for "complete B-cell depletion with clinical response" (CD-R) leads to an optimal management of the disease but unfortunately not all patients maintain this status. Whether CD-R can be regained with RTX retreatment remains unclear.

Objectives: To assess the outcome of RA patients treated with consecutive cycles of RTX, focusing on those who achieved complete B-cell depletion with clinical response.

Methods: A prospective 12 year observational study was conducted in RA patients who were treated with RTX in Leeds. Consecutive cycles of RTX consisting of 2 infusions of $1000 \mathrm{mg}$ were administered either on clinical relapse or a 6-monthly basis. B-cells were measured using highly sensitivity flow cytometry at 0 and 2 weeks post-RTX. Complete depletion (CD) was defined by total B-cell count $<0.0001 \times 10^{9 /} \mathrm{L}$ at week 2. Clinical response was defined by EULAR response criteria and CD-R was seen as the optimal outcome.

Results: 755 patients participated in the study of which 723 had complete data (see fig.1). The mean (range) number of RTX cycles administered was $3.8(1-14) .76 \%(549 / 723)$ of patients reached CD-R at some stage during therapy while $24 \%(174 / 723)$ never did. The latter patients had a shorter period of RTX treatment vs CD-R with an OR of 7.98 after adjusting for age, gender, prior therapy with TNF-I and concomitant DMARDs (95\% Cl 5.86-10.86); $\mathrm{p}<0.001$ (see fig.2). $84 \%$ of those who were retreated with RTX recovered CD-R (77\% of them did it in the following cycle). Half of the patients that reached CD-R maintained it in prospective cycles but $47 \%$ lost it subsequently. A third of the patients that lost either clinical response or B-cell depletion were switched to other medication without receiving further cycles. Overall, at the end of the study, $55 \%$ of all patients treated with RTX (400/723) remained in CD-R.

Conclusion: Most patients treated with RTX will achieve CD-R, but approximately half of them will lose this optimal status at some point. In patients who achieve CD-R but subsequently lose it, retreatment with
RTX appears to be an effective strategy since $80 \%$ of them will regain it and will maintain long-term treatment with therapy

\section{REFERENCES}

[1] Md Yusof, et al. EULAR 2016

[2] Garcia-Montoya, et al. EULAR 2018

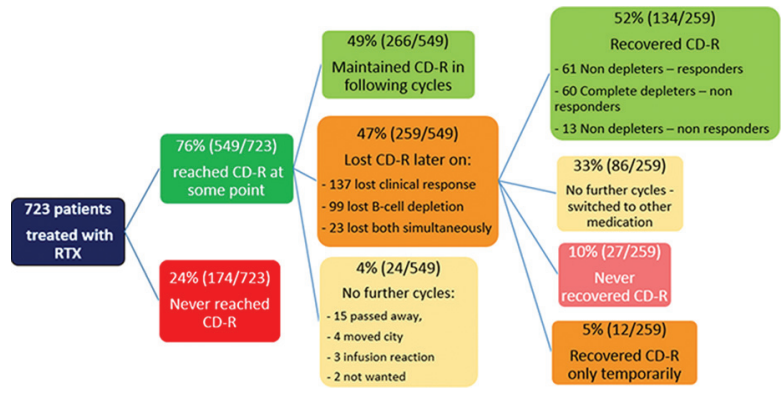

Figure 1

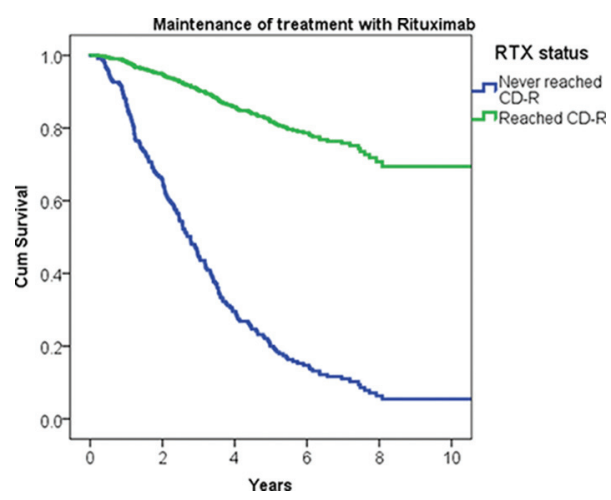

Figure 2

Acknowledgement: Shouvik Dass Maya Buch Sarah Bingham

Disclosure of Interests: Leticia Garcia-Montoya: None declared, Md Yuzaiful Md Yusof: None declared, Jean Baptiste Candelier: None declared, Andrew Rawstron: None declared, Edward Vital Grant/research support from: He has received honoraria and research grant support from Roche, GSK and AstraZeneca., Paul Emery Grant/research support from: Pfizer, MSD, AbbVie, Bristol-Myers Squibb, Roche, Consultant for: Pfizer, MSD, AbbVie, Bristol-Myers Squibb, UCB, Roche, Novartis, Gilead,Samsung, Sandoz and Lilly

DOI: 10.1136/annrheumdis-2019-eular.7601

\begin{tabular}{|l|l}
\hline SAT0145 & ON TAPERING THERAPY FOR RA PATIENTS IN \\
CLINICAL REMISSION; FLARE ON CS-DMARDS IS \\
PREDICTED BY CLINICAL PARAMETERS AND \\
ULTRASOUND, WHEREAS T-CELL ABNORMALITIES \\
ARE PREDICTIVE FOR B-DMARD TAPERING
\end{tabular}

Hanna Gul, Frederique Ponchel, Paul Emery. Leeds Institute of Rheumatic and Musculoskeletal Medicine, Rheumatology, Leeds, United Kingdom

Background: Tapering of disease-modifying therapy (DMARDs) is recommended by EULAR/ACR for rheumatoid arthritis (RA) patients who achieve sustained remission on stable therapy $(1,2)$. However, there is no guidance on how to manage this in clinical practice.

Objectives: We aimed to assess flare over 12 months in RA patients in sustained remission who were offered structured tapering of either conventional synthetic (cs) or biologic (b) DMARDs.

Methods: RA patients (ACR/EULAR 2010) prospectively attending a remission clinic were recruited when fulfilling the criteria of stable remission as defined by 3 -variable DAS28CRP $<2.6$ for $\geq 6$ months (stable therapy \& no corticosteroids). Patients were offered tapering according to a structured protocol (Figure 1). For patients receiving combination cs/bDMARDs, only the b-DMARD was tapered. Clinical, ultrasound (US) + immunological (T-cell subsets: naïve, Treg (both age-corrected) and 